To the Editors:

\title{
Cataracts, health technology and the spectacle of reversely abled generations
}

While sitting for the fourth and the last time (2 parents, 2 eyes each!), with my mother in the medical devices company, to purchase the IntraOcular Lens (IOL) to be used in her cataract operation, I pondered on the advances in technology. My 80-year old parents could now read newspapers without spectacles, but their three middleaged children needed spectacles to read. What next? The Internet mentions replacement hips and spinal discswho knows, when we are 80 years of age our hips and joints might creak less than our children's.

But health technology is not without its problems. Very prominently in front of me was an advertisement with detailed charts and diagrams of the eye and the hues of the rainbow advertising the newest model of the IOL that filtered high-energy blue light. However, what caught my eye were the last two sentences in the advertisement.

"Researchers believe that the blue light may cause damage to the retina which could potentially contribute to macular degeneration or loss of vision. The long-term effects of filtering blue light and clinical efficacy of that filtering on the retina have not been conclusively established."

So, the damage that could occur from blue light is not established and the long term effects of filtering are not known. At least there is no headlong rush based solely on scientific theory without clinical experience. One only needs to be reminded of retrolental fibroplasia leading to blindness after $100 \%$ oxygen in neonatal Intensive care units.

Such "advances" pose not only scientific and clinical questions but also economic ones. The IOL that filtered blue light costs more than the ones that do not. Health Insurance companies in the US will not pay for the IOLs that filter, as they do not have proven benefits. They are "nice to have but not necessary".

When would we know whether or not there was an added advantage? Long term observational studies which will take years would be necessary. Is it reasonable to ask for controlled clinical trials that would take years? Would that inhibit device manufacturers from developing these potentially useful though in the short term unprovable, "advances"? But on the other hand, should the patient pay more for unproven technology?

Perhaps when it is time for my cataract operation they would know; maybe I can ask for the extra cost to be discounted if there was no benefit.

K Weerasuriya, Former Professor of Pharmacology, University of Colombo, Sri Lanka; e-mail:<krisantha@ gmail.com>. 